\title{
BRAÇO ROBÓTICO MICROCONTROLADO PELA PLATAFORMA ARDUINO*
}

\author{
Marcos Danilo Monteiro ${ }^{1}$ \\ José Edleuson de Souza ${ }^{2}$ \\ André Araújo Kuhn Pereira ${ }^{2}$ \\ Marcos de Oliveira Santos ${ }^{3}$ \\ Marinaldo José de Medeiros ${ }^{4}$ \\ Cynthia Marise dos Santos ${ }^{5}$
}

\section{Resumo}

O final do século $X X$ foi marcado por um grande avanço tecnológico em sistemas automatizados com variadas aplicações, dando destaque ao campo da robótica que desde então busca otimizar cada vez mais os processos industriais, eliminado a mão-de-obra humana em segmentos onde sua presença antes era indispensável. $\mathrm{O}$ aumento na qualidade do produto, a relação custo-benefício e dentre outras melhorias que a robótica trouxe a uma linha de produção industrial, justificam a procura por parte das grandes empresas em procurar investir na inserção desta tecnologia ou no melhoramento dela em sua cadeia produtiva. Este trabalho teve como principal objetivo demonstrar a aplicação da tecnologia robótica na indústria, em proporções reduzidas e fins didáticos, com a integração de um sistema de controle e automação representado pela plataforma Arduino que atua no controle de coordenadas de um braço robótico em atividades de carregamento e paletização de cargas.

Palavras-chave: Robótica; Arduino; Automação industrial.

\section{Abstract \\ ROBOTIC ARM MICROCONTROLLED BY ARDUINO PLATFORM}

The late twentieth century was marked by a major technological breakthrough in automated systems with several applications, highlighting the field of robotics has since increasingly seeks to optimize industrial processes, eliminating the hand intensive segments in the human where his presence was indispensable before. The increase in product quality, cost-effective and among other improvements that robotics brought to an industrial production line, justifying the demand from large companies looking to invest in this technology insertion or her improvement in its supply chain. This study aimed to demonstrate the application of robotics technology in the industry, in small proportions and teaching purposes, with the integration of a system of control and automation represented by the Arduino platform that operates in coordinated control of a robotic arm loading activities and palletizing loads.

Keywords: Robotics; Arduino; Industrial automation.

1 Graduando em Eng. Mecânica, Núcleo de Eng. Mecânica, Universidade Federal de Sergipe, São Cristóvão, SE, Brasil.

2 Tecnólogo em Automação Industrial, Mestrando em Mecatrônica, Escola Politécnica, Universidade Federal da Bahia, Salvador, BA, Brasil.

3 Engenheiro Eletricista, Professor efetivo, Instituto Federal de Sergipe, Lagarto, Sergipe, Brasil.

4 Engenheiro Mecânico, Mestre em Eng. Mecânica, Professor efetivo, Instituto Federal de Sergipe, Lagarto, Sergipe, Brasil.

5 Administradora, Mestre em Eng. de Produção, Professora efetiva, Instituto Federal de Sergipe, Lagarto, Sergipe, Brasil.

\footnotetext{
* Contribuição técnica ao $18^{\circ}$ Seminário de Automação e TI Industrial, 23 a 26 de setembro de 2014,
} São Paulo, SP, Brasil. 


\section{INTRODUÇÃO}

O termo em português 'robô' conforme Groover [1] "foi criado por Karel Capek, um novelista e escritor de uma peça teatral da Tchecoslováquia, que usou pela primeira vez, em 1920, a palavra 'robota' (serviço compulsório, atividade forçada) originando a palavra 'robot' em inglês.". A princípio a finalidade dos robôs seria apenas de realizar atividades nas quais exigiriam altos esforços físicos, repetições e outras tarefas impossíveis ao ser humano. No entanto, com os avanços adquiridos, podese observar a atuação deles em diversas áreas, não apenas industrial. Dentre alguns setores: saúde - robôs que realizam cirurgias (monitorados por um especialista), segurança - robôs atuando em desarme de armamentos explosivos, além de outras inúmeras aplicações.

O campo da robótica abrange a eletrônica, a mecânica e a programação, sistemas que reunidos se interagem para controlar e realizar operações automatizadas.

No que se refere ao setor industrial é possível notar a atuação desta tecnologia tanto em indústrias pesadas quanto nas de ponta, são elas: automobilística, siderúrgica, naval, aeroespacial e farmacêutica.

A automação industrial pode ser dividida em três classes: a fixa, a flexível e a programável [4].

A automação fixa é utilizada quando o volume de produção é elevado; sendo que a linha de produção é composta por diversas máquinas de Comando Numérico - CN. A produção é voltada apenas para a confecção de um determinado tipo de produto.

$>$ A automação flexível é utilizada para o volume de produção média, decorrente da área de engenharia mecânica com tecnológicas eletrônicas embarcadas e sistemas de informação. Nesta, é possível que sejam fabricados diversos produtos ao mesmo tempo.

$>$ A automação programável é utilizada para um volume de produção relativamente baixo e diversificado, ou seja, a automação é efetuada em pequenos lotes. Assim, os equipamentos devem ser reprogramados a cada novo lote.

A linha deste trabalho é baseada na terceira definição, pois a robótica é um modelo de automação programável. Dentro da crescente aplicação da robótica na indústria, este projeto visou à construção de um protótipo de um braço mecânico com fins pedagógicos.

Desta forma, o estudo relatado organizou-se nos seguintes tópicos, além da introdução na seção 1 . Na seção 2 é apresentada a parte referente a materiais e métodos. Na seção 3 abordou sobre os resultados e discussões, na seção 4 conclusão, em seguida os agradecimentos e as referências bibliográficas.

\section{MATERIAIS E MÉTODOS}

\subsection{Elementos Constituintes}

Nas subseções abaixo serão abordados as partes constituintes do projeto e suas respectivas finalidade.

\subsubsection{Circuito de controle}

A utilização da plataforma arduino se deveu a facilidade de sua manipulação, não é necessário grande domínio em eletrônica para poder realizar atividades com este microcontrolador.

\footnotetext{
* Contribuição técnica ao $18^{\circ}$ Seminário de Automação e TI Industrial, 23 a 26 de setembro de 2014, São Paulo, SP, Brasil.
} 
O arduino possui diversos modelos que são utilizados conforme as necessidades de cada usuário. Neste trabalho foi escolhida a plataforma Arduino Uno, modelo ATmega328, família AVR, pois possui uma quantidade de portas de entradas e saídas que supre as necessidades desse projeto. Observe a figura abaixo:

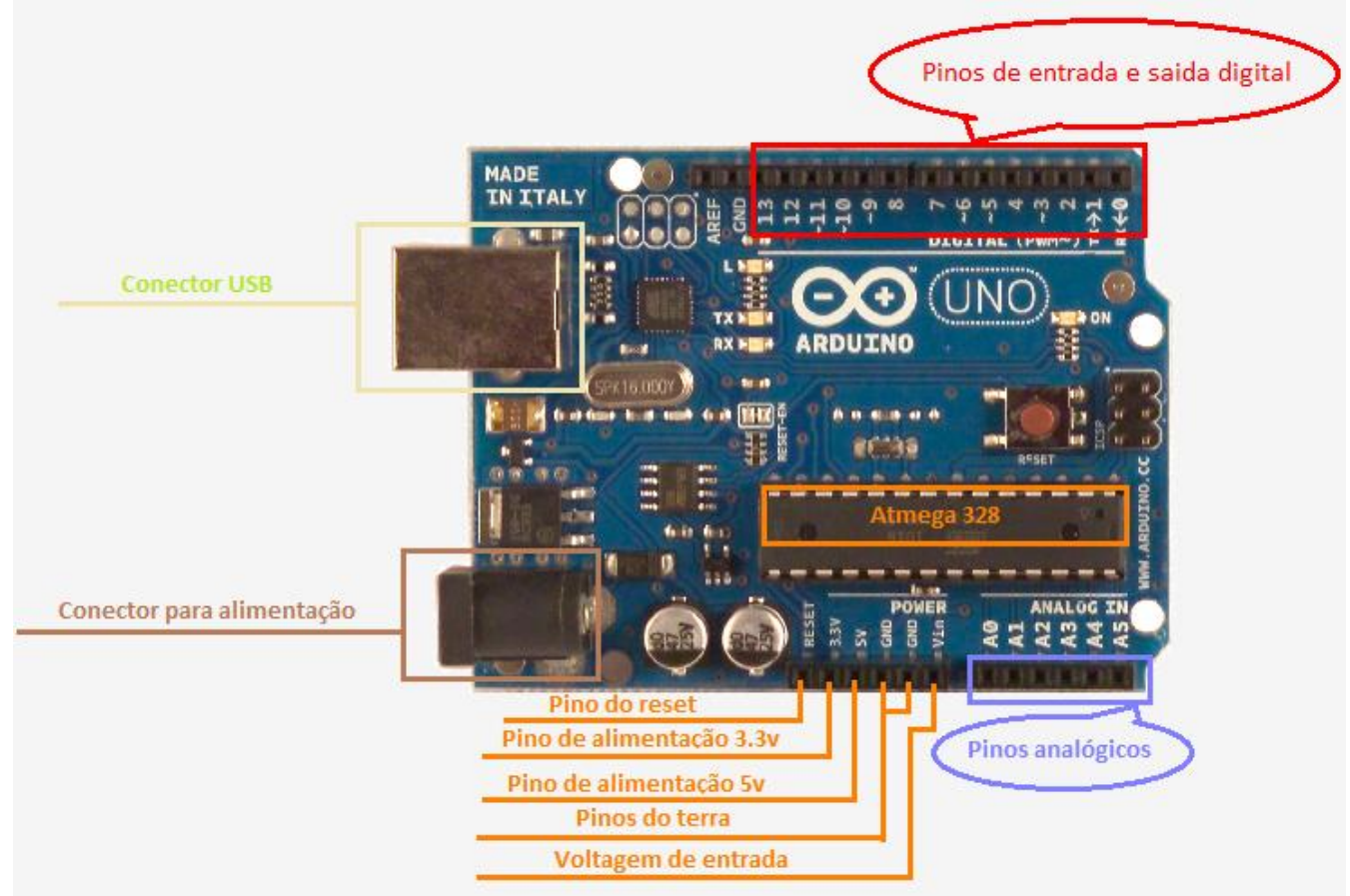

Figura 1. Arduino Uno.

Por se tratar de uma plataforma aberta é possível desenvolver projetos de baixa ou grande complexidade sem necessitar de licença para isso.

\subsubsection{Servomotores}

De acordo Carvalho [3] "O servomotor é uma máquina especial projetada para atender a necessidades específicas que uma máquina síncrona convencional não atenderia.".

A principal característica que diferencia os servomotores dos demais motores síncronos é capacidade dele possibilitar o controle da posição de seu eixo em graus. Para isto, existem três dispositivos internos ao servo que são essenciais para este controle, são eles:

- Um motor elétrico, em geral CC, que serve como sistema atuador;

- Uma caixa de redução que auxilia na amplificação do torque e;

- Um potenciômetro que faz o papel de um sensor e juntamente ao eixo do motor indica a posição angular deste.

Observe a figura do modelo dos três servomotores logo abaixo:

* Contribuição técnica ao $18^{\circ}$ Seminário de Automação e TI Industrial, 23 a 26 de setembro de 2014, São Paulo, SP, Brasil. 


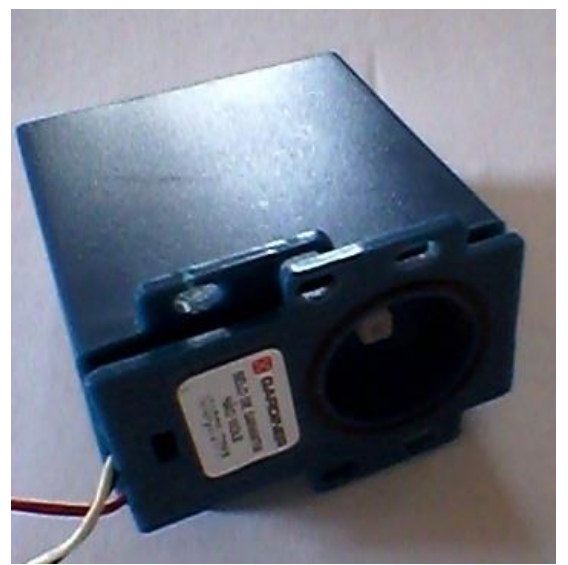

Figura 2. Servomotor - Modelo 134 Gardiner.

O projeto consiste em paletizar cargas utilizando um braço robótico composto por uma base fixa, 09 elos, 11 juntas e uma configuração GL de três graus de liberdade. O movimento entre os elos é feito através da variação dos servomotores que são controlados pela plataforma arduino. O valor atribuído a esses ângulos são obtidos por meio de cálculos trigonométricos e vetoriais realizados após se ter as coordenadas de um determinado ponto onde se deseja alcançar com o robô e assim inseridos no programa do controlador. Na subseção 2.2 serão abordados os métodos matemáticos que foram necessários para se chegar aos respectivos pontos.

\subsubsection{Software de Modelagem Estrutural}

A ferramenta utilizada para modelagem do protótipo e descrição dos cálculos vetoriais e trigonométricos foi o programa Solidworks Premium $2012 \AA$ versão trial. Segundo Souza [5], "O Solidworks é um software de CAD (Computer Aided Design) específico para modelagem sólida paramétrica variacional, tem como finalidade 0 desenvolvimento de desenhos ou projetos em 2D (duas dimensões) ou 3D (três dimensões).".

Observe a figura a seguir do protótipo:

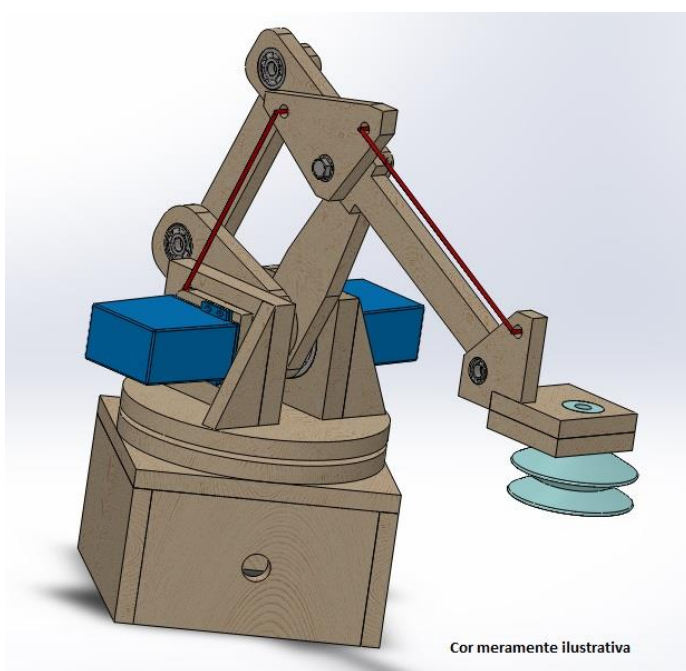

Figura 3. Desenho do Braço Robótico.

O material que compõe a estrutura do braço é de madeira, denominada Pinho, a escolha se deveu a sua baixa densidade em relação às demais opções.

* Contribuição técnica ao $18^{\circ}$ Seminário de Automação e TI Industrial, 23 a 26 de setembro de 2014, São Paulo, SP, Brasil. 


\subsubsection{Sensor Ótico}

$\mathrm{Na}$ concepção de Kilian [2], "Sensores são equipamentos pelos quais o controlador monitora o processo.". Em todo o processo de automação a inserção desses elementos é essencial para se conseguir monitorar todas as informações e distúrbios de um dado evento.

Há sensores das mais variadas finalidades, neste projeto foi utilizado o sensor ótico (conhecido também como sensor fotoelétrico). Sua funcionalidade consiste em detectar partes e peças por meio da emissão e recepção de feixes de luz. Com referência ao sensor relatado existem três métodos de captação: Retroreflexivo: onde a detecção de objetos é feita com espelho refletor. Feixe Unidirecional: cujo modo de detecção é feito através da interrupção de um feixe de luz. Difuso: onde a detecção de objetos opacos é feita sem necessidade de outros dispositivos. Observe abaixo a imagem do sensor utilizado:

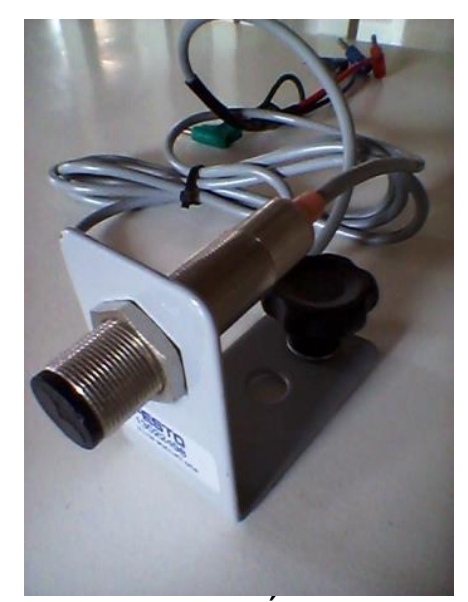

Figura 4. Sensor Ótico da Festo.

O método de detecção do sensor desta pesquisa foi o difuso.

\subsubsection{Circuito de Potência}

O sistema que compõe a parte ligada ao acoplamento do produto pela garra do braço foi por sucção pneumática. Assim, foi preciso incluir um circuito que servisse de interface entre a parte de controle (5Vcc) e de acionamento (24Vcc).

Observe a figura abaixo do circuito de acionamento dos relés:

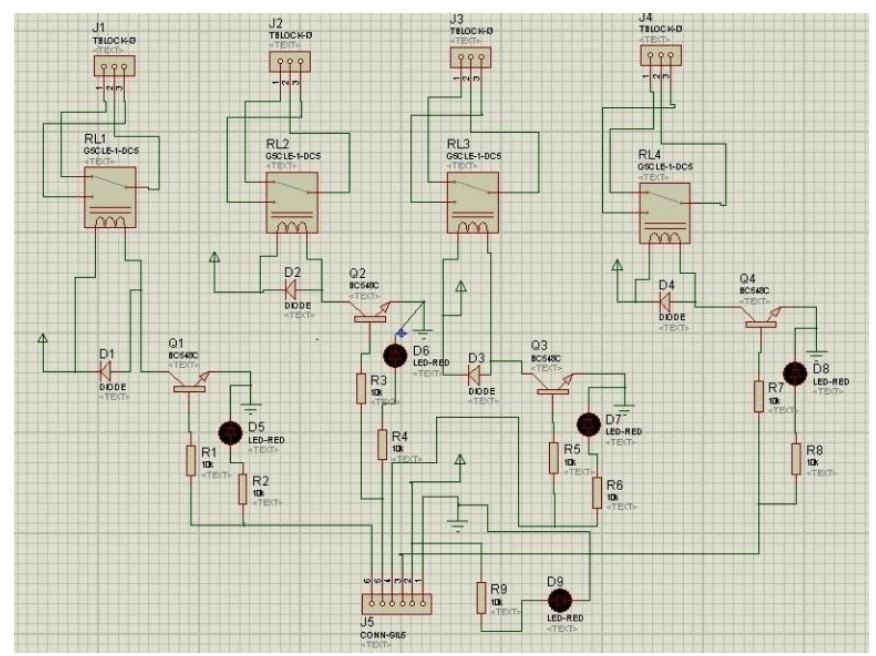

Figura 5. Circuito de Potência no Proteus 7.7.

* Contribuição técnica ao $18^{\circ}$ Seminário de Automação e TI Industrial, 23 a 26 de setembro de 2014, São Paulo, SP, Brasil. 
É possível visualizar na figura acima quatro relés eletromecânicos de 5Vac $110 \mathrm{Vac} / 10 \mathrm{~A}$, dois foram utilizados no acionamento dos solenoides da válvula pneumática. Já os outros relés foram inseridos no processo de confecção da placa tendo em vista uma futura expansão do respectivo projeto. Também fazem parte do circuito os seguintes componentes: quatro diodos 1N4001, quatro transistores LM548 e cinco leds que servem de visualização no processo de comutação dos relés.

\subsubsection{Circuito Eletropneumático}

O circuito eletropneumático deste trabalho se comporta da seguinte maneira conforme figura abaixo:

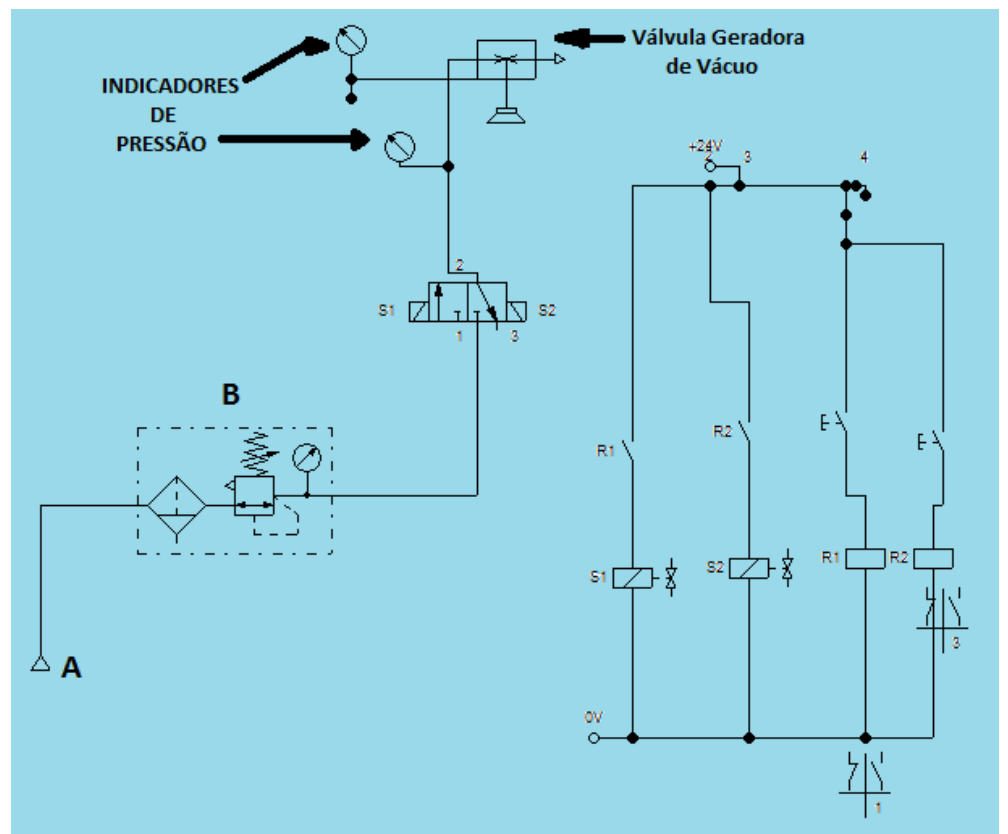

Figura 6. Circuito Eletropneumático no FluidSIM 3.6.

O ar que está armazenado no compressor A, após ser liberado é enviado para unidade de conservação de ar comprimido B. Em seguida penetrará na válvula pneumática, ao chegar dentro dela esse ar será ou não obstruído conforme o acionamento dos solenoides $\mathrm{S}_{1}$ ou $\mathrm{S}_{2}$.

Caso o ar não sofra obstrução, este seguirá pelo circuito, passando por indicadores de pressão até alcançar uma válvula geradora de vácuo. Esta válvula tem a finalidade de gerar um vácuo necessário para sucção pneumática que acoplará a produto da linha de produção ao braço robótico e seguirá seu destino préprogramado.

\subsection{Métodos Matemáticos}

Nesta seção serão descritos os métodos de cálculo das coordenadas de um determinado ponto onde se deseja alcançar com o braço robótico.

A trigonometria, geometria e cálculo vetorial são ferramentas essenciais na obtenção dessas coordenadas. Com a utilização destes conceitos foi possível encontrar tais valores. Demonstrados através das seguintes deduções.

* Contribuição técnica ao $18^{\circ}$ Seminário de Automação e TI Industrial, 23 a 26 de setembro de 2014, São Paulo, SP, Brasil. 
Cada ponto $\mathrm{P}(\mathrm{x}, \mathrm{y}, \mathrm{z})$ do espaço irá corresponder ao vetor que se segue na figura abaixo:

$$
\overrightarrow{O P}=x \vec{i}+y \vec{j}+z \vec{k}
$$

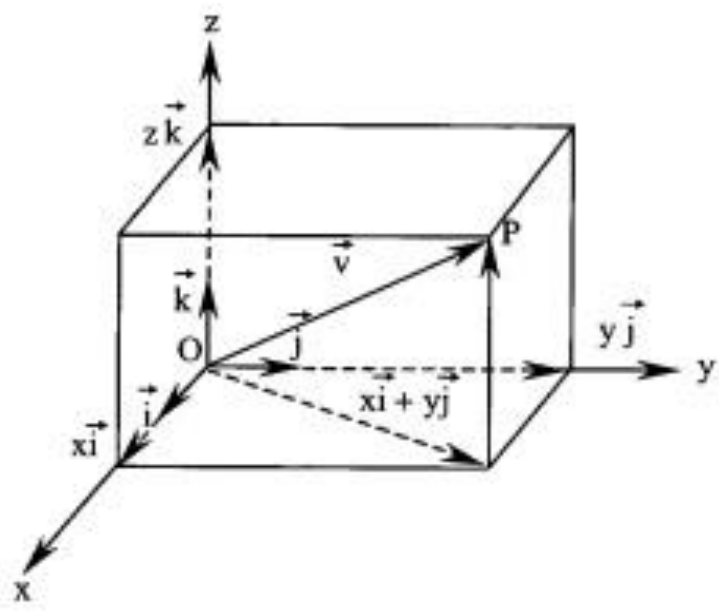

Figura 7. Cubo Vetorial [6].

$\mathrm{Na}$ figura seguinte é possível perceber que as hastes do robô correspondem a vetores. Então, utilizando os cálculos vetoriais necessários obtêm-se as coordenadas de orientação dos movimentos do braço.

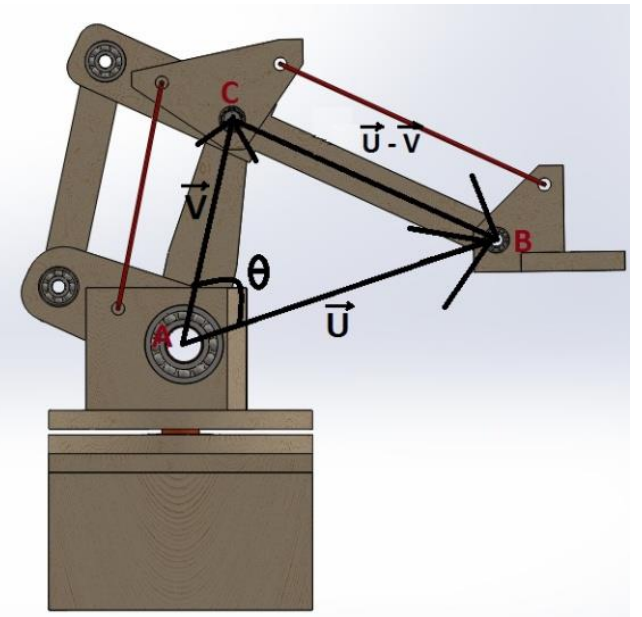

Figura 8. Vetores do braço mecânico.

O ponto B é a onde o braço irá erguer ou descartar a carga, já o ponto A é o centro de gravidade da base do eixo. É neste local que o protótipo se comporta como se todo o peso dele estivesse concentrado nele. O módulo de $\vec{U}$ é a distância entre o eixo central do braço robótico ao ponto B de coordenadas $(214,35) \mathrm{mm}$, ponto onde se deseja alcançar com o braço robótico.

* Contribuição técnica ao $18^{\circ}$ Seminário de Automação e TI Industrial, 23 a 26 de setembro de 2014, São Paulo, SP, Brasil. 


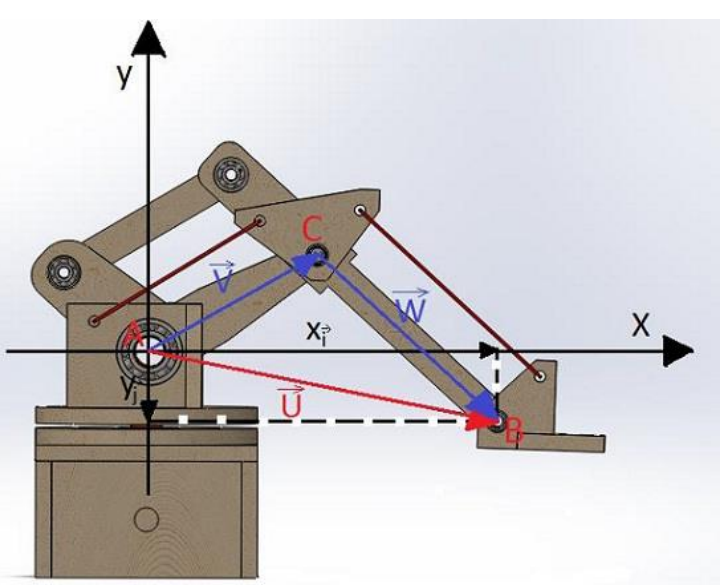

Figura 9. Vista lateral inclinada.

Cálculo do módulo de $\vec{U}$ :

$$
\begin{aligned}
|U| & =\sqrt{x t^{2}+y j^{2}} \\
|U| & =\sqrt{214^{2}+35^{2}} \\
|U| & =216,85 \mathrm{~mm}
\end{aligned}
$$

Como os valores de $\vec{v}$ e $\vec{w}$ respectivamente são $122 \mathrm{~mm}$ e $155 \mathrm{~mm}$ e correspondentes as dimensões das hastes do braço robótico, após conseguir o valor do módulo de $\vec{U}$, foi possível obter as medidas do triângulo $A B C$ da figura 10 . Com o módulo dos três vetores, aplicando a lei dos cossenos ao triângulo $A B C$, se encontrou os ângulos internos do mesmo.

Lei dos cossenos ou teorema dos cossenos de um triângulo $A B C$ :

$$
\begin{aligned}
& a^{2}=b^{2}+c^{2}-2 b c \cos A \\
& b^{2}=a^{2}+c^{2}-2 a c \cos B \\
& c^{2}=a^{2}+b^{2}-2 a b \cos C
\end{aligned}
$$

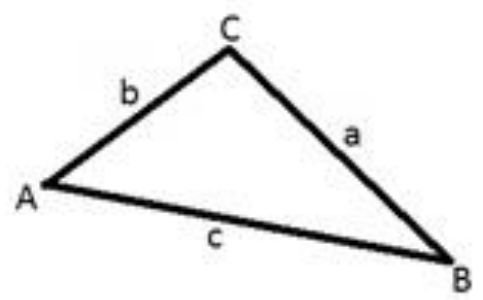

Figura 10. Triângulo ABC.

Substituindo as letras e comparando o triângulo acima com o triângulo da figura 11, temos por analogia as seguintes equações:

$$
\begin{aligned}
& w^{2}=v^{2}+u^{2}-2 v u \cos A \\
& v^{2}=w^{2}+u^{2}-2 w u \cos B \\
& u^{2}=w^{2}+v^{2}-2 w v \cos C
\end{aligned}
$$

* Contribuição técnica ao $18^{\circ}$ Seminário de Automação e TI Industrial, 23 a 26 de setembro de 2014, São Paulo, SP, Brasil. 


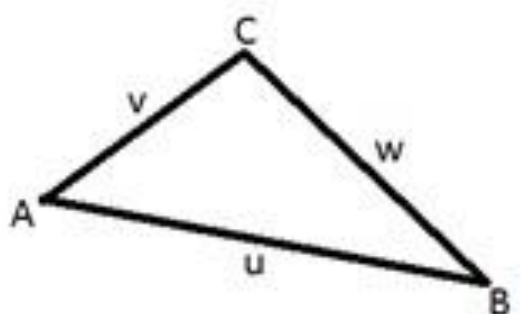

Figura 11. Por semelhança de triângulos.

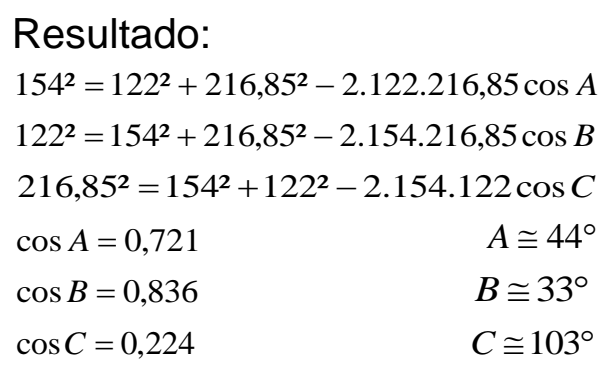

Com a haste correspondente ao vetor $\vec{v}$ no momento inicial de qualquer movimento do braço robótico é coincidente ao eixo y e varia ângulo $\varnothing$ desejado (Figuras $12 \mathrm{e}$ 13). O ângulo ø é encontrado através dos seguintes cálculos:

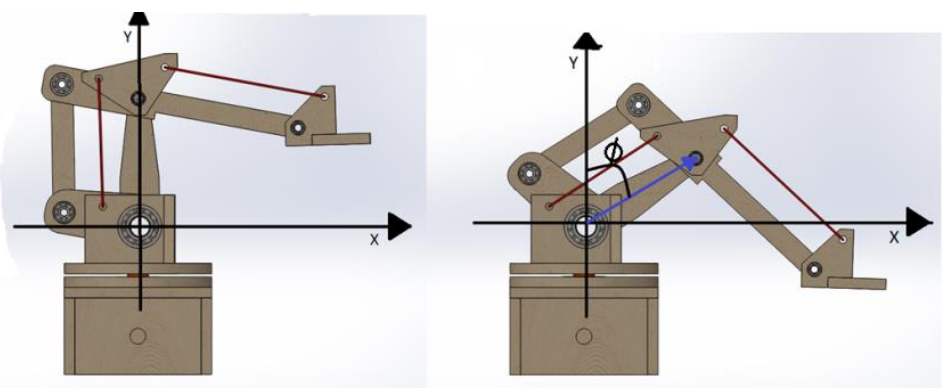

Figura 12. Ângulo ø.

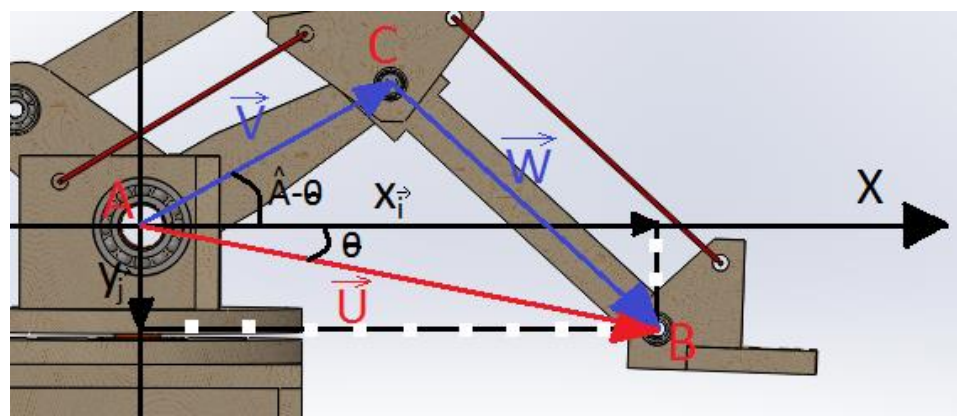

Figura 13. Coordenadas vetoriais.

$$
\sin \theta=\frac{35}{216,85}=0,161
$$

$$
\begin{aligned}
& \sin \theta=9,28^{\circ} \\
& \phi=90^{\circ}-(A-\theta) \\
& \phi=90^{\circ}-\left(43,79^{\circ}-9,28^{\circ}\right) \\
& \phi=55,5^{\circ}
\end{aligned}
$$

* Contribuição técnica ao $18^{\circ}$ Seminário de Automação e TI Industrial, 23 a 26 de setembro de 2014, São Paulo, SP, Brasil. 
A haste representada pelo segmento EA gera o movimento na haste representada pelo segmento DB através da haste ED da figura 14. Como as hastes possuem um sistema trigonométrico interligado, o posicionamento das mesmas é definido pelas coordenadas do vetor $\vec{U}$. O ângulo $\gamma$ é o ângulo de giro que o motor interligado a haste EA realiza para obter o posicionamento final das hastes e foi calculado da seguinte forma.

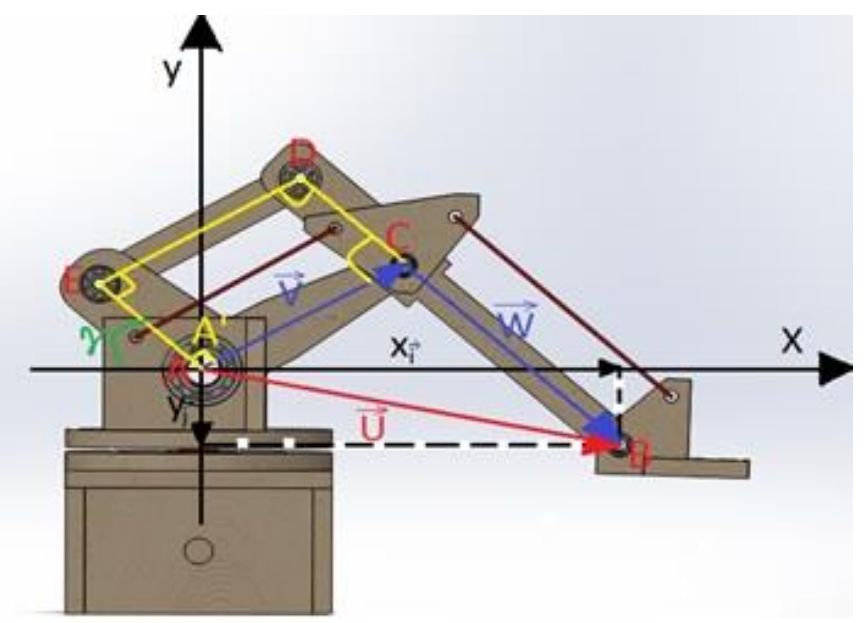

Figura 14. Ângulo de Giro.

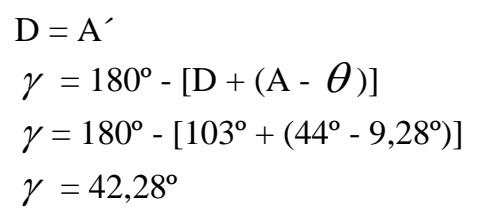

O valor da coordenada $X_{i}$ do vetor $\vec{U}$ equivale ao raio onde o braço robótico poderá trabalhar ao redor de sua base de acordo com as coordenadas predeterminadas e não pode variar acima de um ângulo limite em que o servomotor utilizado pode trabalhar. A figura 15 demonstra uma melhor visualização do sistema.

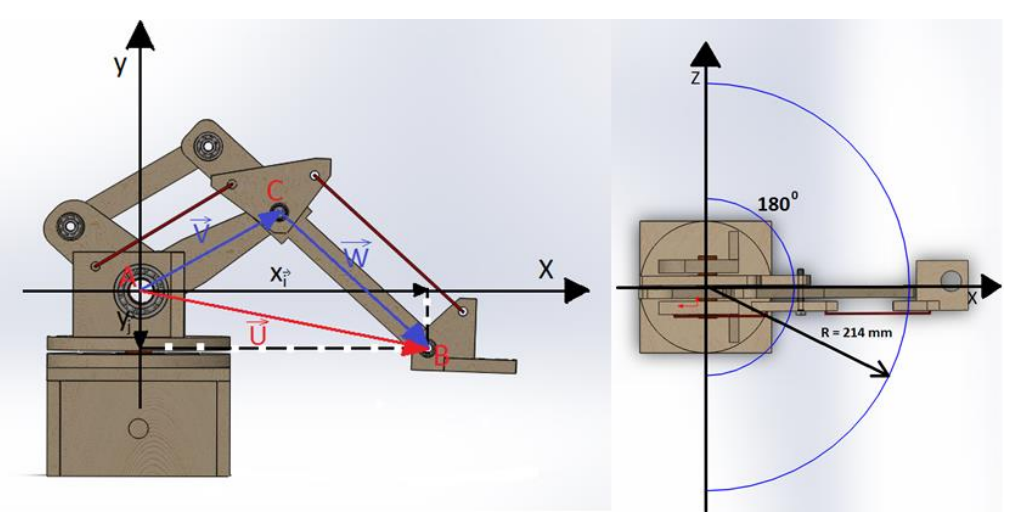

Figura 15. Coordenada $X_{i}$

Após haver encontrado os valores de todos os ângulos necessários para que o braço robótico pudesse realizar a sua ação de trabalho e inserir os valores desses ângulos no programa da plataforma arduino (figura 16) o projeto chegou a sua fase final.

\footnotetext{
* Contribuição técnica ao $18^{\circ}$ Seminário de Automação e TI Industrial, 23 a 26 de setembro de 2014, São Paulo, SP, Brasil.
} 

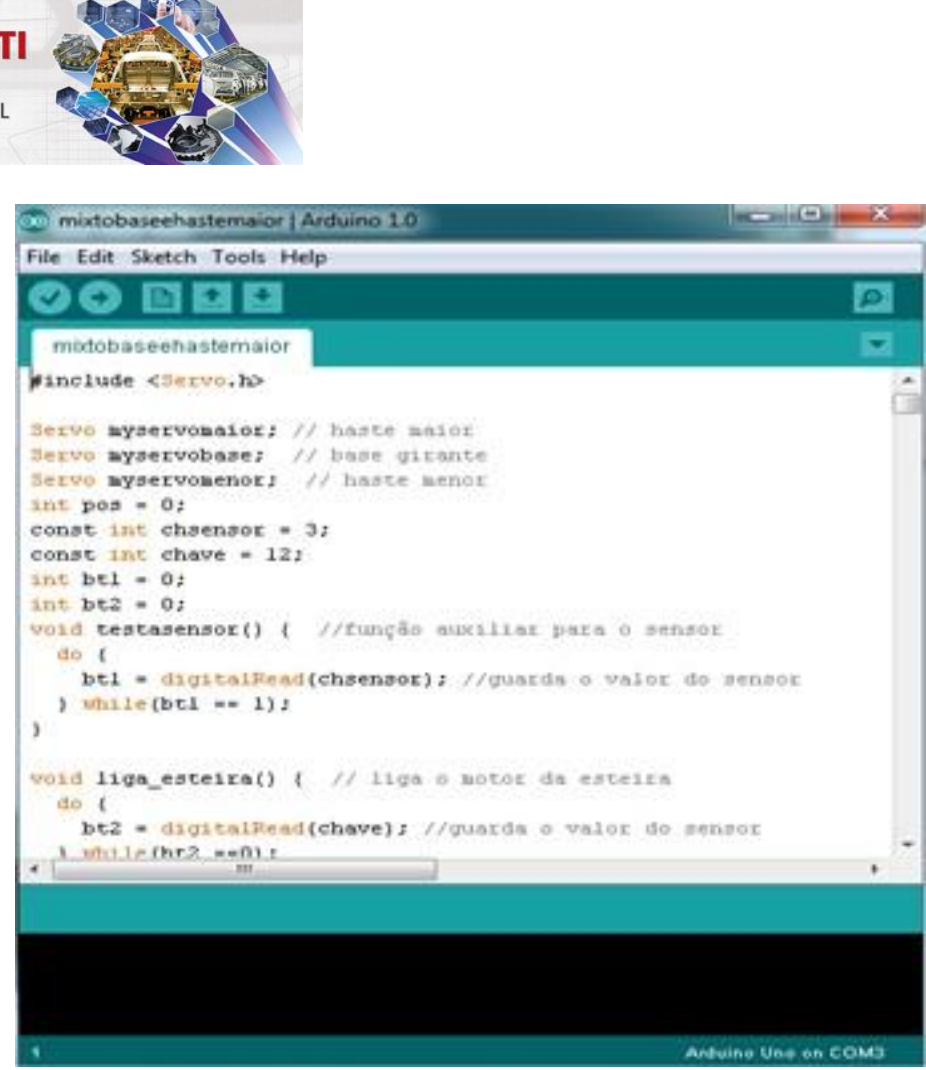

Figura 16. Algoritmo do projeto na tela do Arduino 1.0.

\section{RESULTADOS E DISCUSSÃO}

Braços articulados são utilizados no setor industrial em larga escala devido não apenas a sua polivalência, mas também por possuir maior poder de precisão e produção em relação ao trabalho humano.

Observe na figura abaixo a estrutura do sistema:

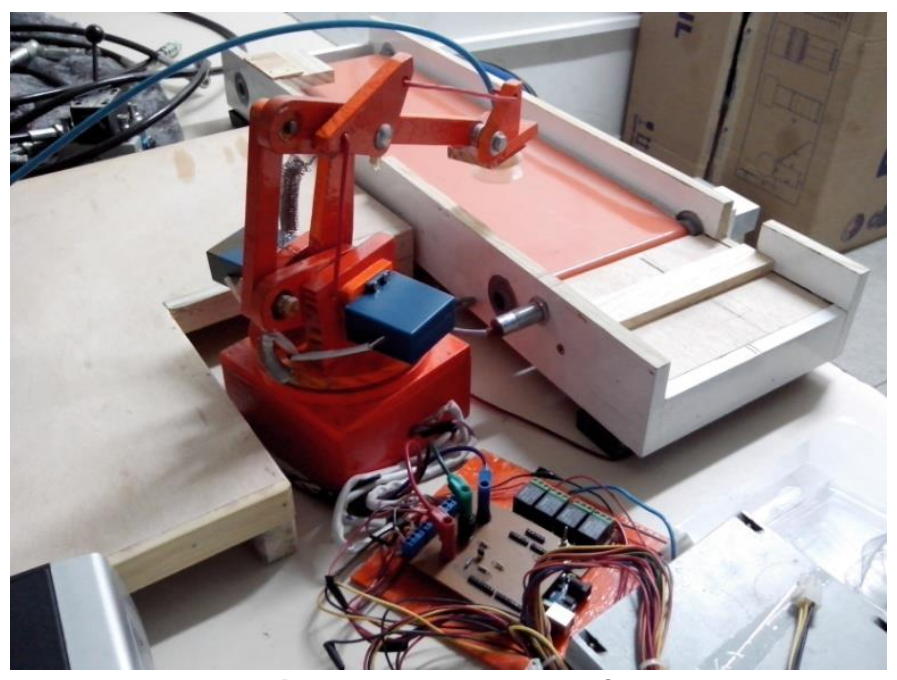

Figura 17. Braço Robótico.

Através dos ensaios realizados em laboratório, com a utilização de medidores de comprimento (trena) e de ângulo (goniômetro), foi possível observar imprecisões nas atividades do protótipo. Dentre os erros: pequenas falhas de medição cometidas no início de execução da construção mecânica do projeto, aliado a uma falta de maior precisão do servomotor. Fatores estes que influenciaram em um pequeno desvio dos resultados previstos nos cálculos das coordenadas obtidas. Por outro lado, no que se refere à programação do arduino, não houve problemas relevantes,

* Contribuição técnica ao $18^{\circ}$ Seminário de Automação e TI Industrial, 23 a 26 de setembro de 2014, São Paulo, SP, Brasil. 
apresentando um desempenho satisfatório conforme as reais necessidades do trabalho.

Utilizando a plataforma arduino e os servomotores mais potentes e com maior precisão, o principal trabalho futuro é desenvolver um braço robótico que possua maior exatidão e suporte a elevação de cargas pesadas. Visto que este protótipo é didático e eleva pequenas cargas.

\section{CONCLUSÃO}

O protótipo elaborado e relatado neste trabalho possibilitou o estudo de diversos dispositivos e a aprendizagem de suas características de funcionalidade em áreas que se interagem no campo da automação industrial. Assim, pode-se observar a presença de sistemas de controle, eletropneumático, eletrônico, softwares de programação (em linguagem gráfica e de texto) e a aplicação de métodos matemáticos da engenharia. Desta forma, foi possível aliar todas as capacidades individuais na busca pelo desenvolvimento de um projeto multidisciplinar.

\section{Agradecimentos}

O grupo de pesquisadores agradecem ao Instituto Federal de Sergipe, a Universidade Federal de Sergipe e a Universidade Federal da Bahia por permitirem acesso aos meios laboratoriais e bibliográficos para construção deste protótipo.

\section{REFERÊNCIAS}

1 Groover MP, Weiss M, Nagel RN, Odrey NG. Robótica, Tecnologia e Programação. São Paulo: McGaw-Hill; 1988.

2 Killian CT. Modern Control Technology: Components and Systems. Delmar Thomson Learning, $2^{\text {nd }}$ Edition; 2000.

3 Nascimento Jr GC. Máquinas Elétricas: Teoria e Ensaios. São Paulo: Érica, 2ª Edição; 2007.

4 Rosario JM. Princípios de Mecatrônica. São Paulo: Pearson Education; 2005.

5 Souza AC, Speak HJ, Gómez LA, Rohleder E. Guia Prático para Modelagem Sólida. Florianópolis: Visual Books; 2000.

6 Winterle P. Vetores e Geometria Analítica. São Paulo: Pearson Makron Books; 2000.

* Contribuição técnica ao $18^{\circ}$ Seminário de Automação e TI Industrial, 23 a 26 de setembro de 2014, São Paulo, SP, Brasil. 